\title{
Targeting Prostate Cancer with a Combination of WNT Inhibitors and a Bi-functional Peptide
}

\author{
CALOGERO S. MESSINA ${ }^{1,2}$, HANS WEIHER $^{2}$ and INGO G.H. SCHMIDT-WOLF ${ }^{1}$ \\ ${ }^{1}$ Center for Integrated Oncology (CIO), Department of Internal Medicine III, University Hospital Bonn, \\ Rheinische Friedrich Wilhelm University Bonn, Bonn, Germany; \\ ${ }^{2}$ Bonn-Rhein-Sieg University of Applied Sciences, Rheinbach, Germany
}

\begin{abstract}
Background/Aim: Prostate cancer is the most common cancer in the Western world. A bi-functional peptide was combined with wingless-related integration site (WNT) inhibitors to determine if there is an additive therapeutic effect when they are used against prostate cancer, since their efficacy has already been proven when used alone. Materials and Methods: A bi-functional peptide (TP-LYT) was designed with a target domain (LTVSPWY) and a lytic domain $(K L A K L A K)_{2}$, and a second peptide with the same lytic domain but a random sequence instead of the target domain was used as a negative control. Two different WNT inhibitors were used, ethacrynic acid and ciclopiroxolamine. They were tested on prostate cancer cells using the WST-8 assay. Results: A synergistic effect of peptides and WNT inhibitors was demonstrated, increasing the toxicity against cancer cells. Conclusion: Our findings potentially allow safer treatment since lower concentrations of WNT inhibitors can be used in combination with this bi-functional peptide.
\end{abstract}

Prostate cancer is the third most common cause of cancer in Europe for males, and the sixth most common cause of cancer death overall, with around 92,300 deaths from prostate cancer in 2012 (1). There is increasing emphasis being placed on therapies that allow for eradication of cancer with fewer side-effects and complications. The winglessrelated integration site (WNT)/ $\beta$-catenin pathway is a hopeful target for therapy since it plays an important role during proliferation, differentiation and apoptosis of cells (2, 3 ). Deregulation of this pathway is frequently observed in

Correspondence to: Professor Dr. Ingo G.H. Schmidt-Wolf, Center for integrated Oncology (CIO), University Hospital Bonn SigmundFreud-Straße 25, 53105 Bonn Germany. Tel: +49 22828717050, Fax: +49 2282879080059, e-mail: Ingo.Schmidt-Wolf@ukb.unibonn.de

Key Words: Prostate cancer, WNT inhibitors, targeted therapy, bifunctional peptide. several types of cancer and it is thought to be an initiator of tumorigenesis (4-7).

In the present study, we used two different WNT inhibitors, ethacrynic acid (EA) and ciclopirox olamine (CIC). EA, already used clinically as a diuretic agent, inhibits glutathione- $S$-transferase (GST). GST is overexpressed in human tumors leading to an excess of glutathione (GSH), which binds to electrophilic compounds in detoxification in the cell (8). EA binding to GSH enhances the cytotoxicity of chemotherapeutic agents (9). CIC is used as an antifungal agent for the treatment of yeast infections in humans. It is a chelator of polyvalent metal cations (e.g. $\mathrm{Fe}^{3+}$ and $\mathrm{Al}^{3+}$ ), inhibiting the metal-dependent enzymes in metabolism of the cell. Moreover, it blocks the cell cycle near the $\mathrm{G}_{1} / \mathrm{S}$ phase boundary (10).

In addition to WNT inhibitors, two peptides were used in this study. The design of peptides smaller than antibody-drug conjugates (ADC) is of paramount importance in overcoming size restrictions. TP-LYT is a bi-functional peptide with two different domains, one is the lytic domain (KLAKLAK) which has been shown to disrupt mitochondrial membranes once it has been internalized as it destroys negatively-charged membranes and this kind of membrane has a high content of anionic phospholipids (11). The second part of TP-LYT is the target domain (LTVSPWY), important for enhancing toxicity towards tumor cells (12-15). This particular sequence was chosen because it selectively binds to cancer cells but not to healthy cells (16-20). The two domains are joined using a glycin-glycin linker (Figure 1) (13). The second peptide was p34 and was used initially as the control peptide.

In this project, we wished to determine whether or not there is an additive effect on cytotoxicity when bi-functional peptide and WNT inhibitors are used in combination since they have different targets.

\section{Materials and Methods}

Cell and culture conditions. Five different prostate cancer cell lines (see below) and one primary cell line (CCD18co) were used. BM1604, 22Rv1, LNCaP and PC3 cell lines were obtained from Deutsches 
Krebsforschungszentrum (DKFZ Heidelberg, Germany). DU145 and CCD18co were present in our laboratory (DKFZ, Heidelberg, Germany). All the cells were incubated at $37^{\circ} \mathrm{C}$ in $5 \% \mathrm{CO}_{2}$ and $90 \%$ humidity. The cancer cell lines DU-145, BM-1604, 22Rv1 and LNCaP were cultured in Roswell Park Memorial Institute 1640 medium (PAN Biotech Aidenbach, Germany) supplemented with $10 \%$ fetal calf serum (FCS) and $1 \%$ penicillin/streptomycin (P/S). The cancer cell line PC-3 was cultured in Dulbecco's modified Eagle's Medium (Gibco, Carlsbad, CA, USA) supplemented with 10\% FCS and 1\% $\mathrm{P} / \mathrm{S}$. The primary cell line CCD18co was cultured in Eagle's minimal essential medium supplemented with $10 \%$ FCS and $1 \% \mathrm{P} / \mathrm{S}$.

Peptides and chemical agents. All drugs and peptides were tested with an incubation time of $24 \mathrm{~h}$ at different concentrations. The peptides were synthesized by and purchased from ThermoFisher (Ulm, Germany) and delivered as lyophilized powder. Both peptides were dissolved in isotonic phosphate-buffer saline and stored at $-80^{\circ} \mathrm{C}$. EA and CIC were purchased from Sigma-Aldrich (Steinheim, Germany). They were dissolved in phosphate-buffered saline (PBS) and stored at $-20^{\circ} \mathrm{C}$.

Cell viability assay with 2-(2-methoxy-4-nitrophenyl)-3-(4nitrophenyl)-5-(2,4-disulfophenyl)-2H-tetrazolium, monosodium salt (WST-8) assay. Viability and proliferation of the different cell lines, after treatment with WNT inhibitors and peptides, were assessed by WST-8 assay (Dojindo Molecular Technologies Inc., Rockville, MD, USA). WST-8 is reduced by dehydrogenases in cells giving an orange colored product and the amount of which is directly proportional to the number of living cells. All experiments were performed in triplicate wells for each condition. DU145, BM1604, 22Rv1, LNCaP and CCD18co were plated at $1 \times 10^{4}$ cells in $100 \mu \mathrm{l} /$ well in 96-well plates and left to adhere overnight in an incubator. PC3 cell line was plated at $5 \times 10^{3}$ cells in $100 \mu \mathrm{l} /$ well in 96 -well plates. The following day, the medium was removed and fresh medium containing different concentrations of TP-LYT, p34, EA and CIC, singularly and in combination were added to the cells. After $22 \mathrm{~h}, 10 \mu \mathrm{l}$ of tetrazolium solution was added to each well and after $2 \mathrm{~h}$ the absorbance was recorded at $450 \mathrm{~nm}$ using a BMG FLUOstar OPTIMA Microplate Reader and analyzed using Prism 6 (GraphPad Software, La Jolla, CA, USA). Media and cells without drugs were used as controls and only the media and PBS for the blanks.

Statistical analysis. Statistical analysis was performed using Prism 6 (GraphPad Software, La Jolla, USA). Student $t$-test was used to compare cell viability under different treatments. The significance level in this study was set at 0.05 .

\section{Results}

Cytotoxic effects of TP-LYT, p34, EA and CIC on prostate cancer cell lines DU145, BM1604, 22Rv1, LNCaP and PC3 were investigated and compared to the primary cell line CCD18co using the cytotoxicity assay cell counting kit- 8 (CCK-8) after exposure for $24 \mathrm{~h}$. All results are shown as percentage of the cell viability.

Toxicity of the bi-functional peptide towards prostate cancer cells. Firstly, the different cell lines were treated with TPLYT and p34 separately. Figure 2 shows the viability after

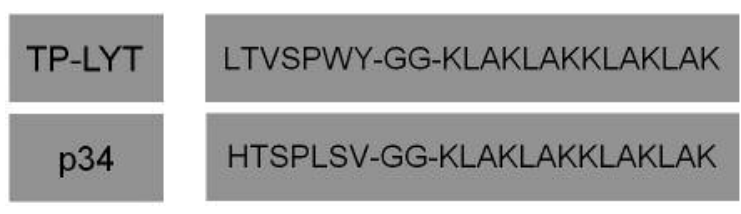

Figure 1. Amino acid sequence of the peptides used in this study.

$24 \mathrm{~h}$ of incubation with the peptides. p34, initially used as control peptide, surprisingly exerted higher cytotoxicity towards most cell lines than TP-LYT. Both peptides were toxic towards the different prostate cancer cell lines, and TPLYT also reduced the viability of the control cell line CCD18co. The concentrations used were the same as used in previous work $(21,22)$.

Toxicity of the WNT inhibitors towards prostate cancer cells. Secondly, EA and CIC were used to treat the prostate cancer cell lines and CCD18co to monitor the cytotoxicity when used alone. Figure 2 shows the viability after $24 \mathrm{~h}$ of incubation with EA, and CIC alone. Both exhibited toxicity towards the different prostate cancer cell lines, and CIC also reduced the viability of the control cell line CCD18co by $50 \%$. The concentrations used were the same as used in previous work $(21,22)$.

Combination of WNT inhibitors and the peptides. After testing the effects of the single active substances, the five different cell lines were treated using the peptides in combination with the WNT inhibitors to investigate if the cytotoxic effects were additional and if the effectiveness was different from cell line to cell line.

As depicted in Figure 2, it is evident that the combined treatment of peptide TP-Lyt and WNT inhibitors led to more potent killing activity than when cells were treated with only one compound. Analogously, when p34 and WNT inhibitors were combined, cytotoxicity was also stronger. In both cases, this activity was stronger against prostate cancer cells than control cells (Figure 2). The concentrations used were the same as those used in previous work $(21,22)$.

\section{Discussion}

TP-LYT, p34, EA and CIC were clearly cytotoxic towards the five prostate cancer cell lines used in this study (Figure 2). Cytotoxicity of TP-LYT could be expected since is made up of two already known domains. TP (LTVSPWY) is the targeting domain since it has been shown to bind to cancer cells and not to normal cells (16-20), and the lytic domain (KLAKLAK)2 which is able to induce cell death after disrupting mitochondrial membranes, due to their negatively 
A

DU145

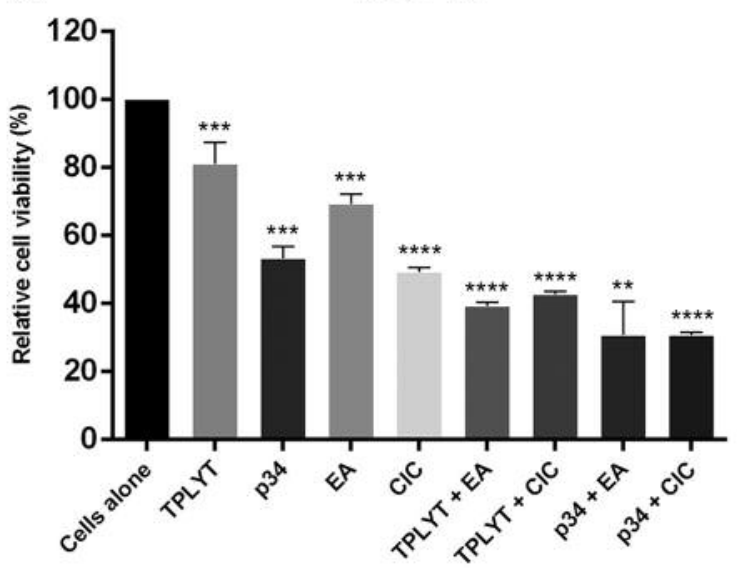

C

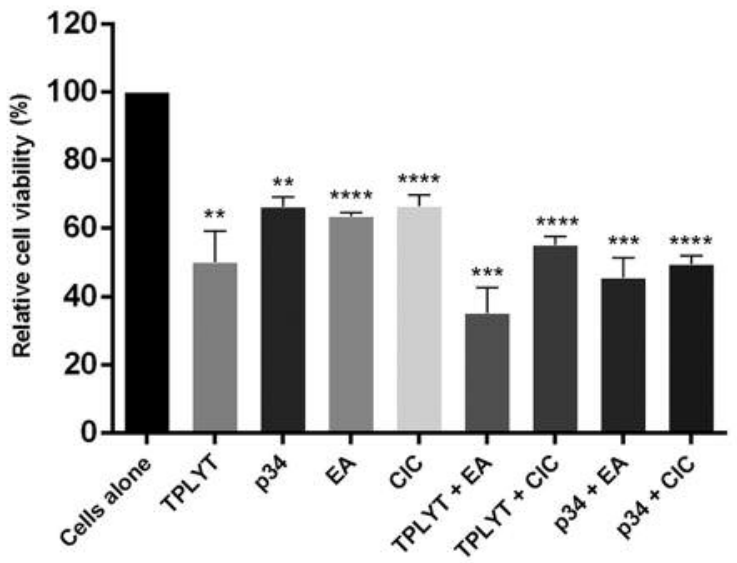

E

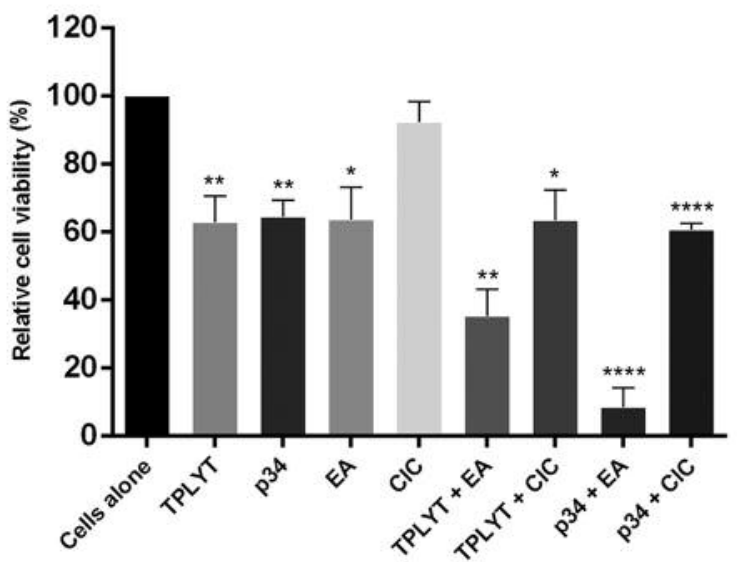

B

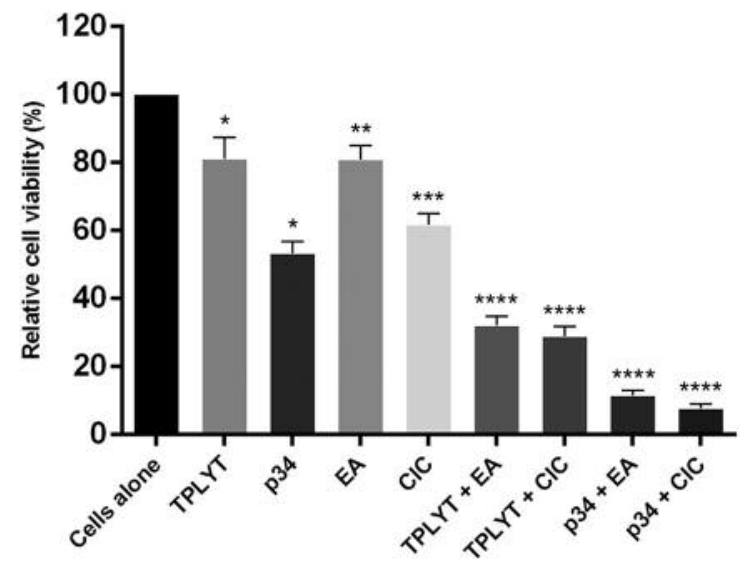

D

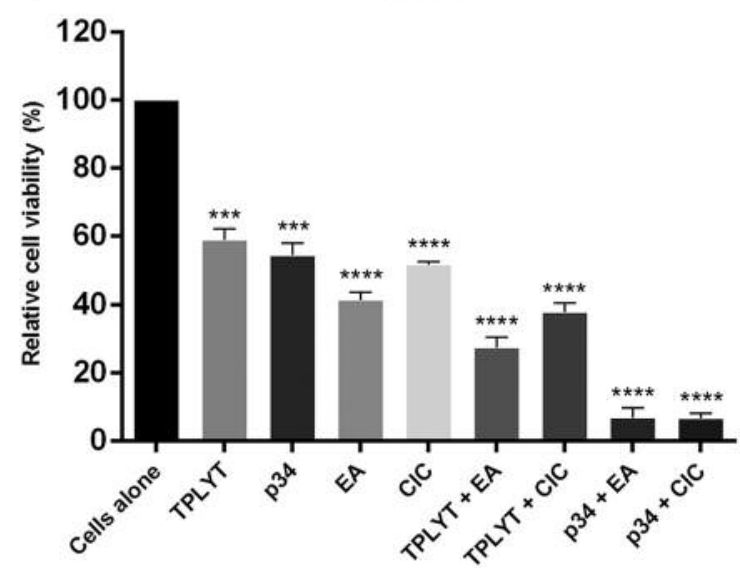

F

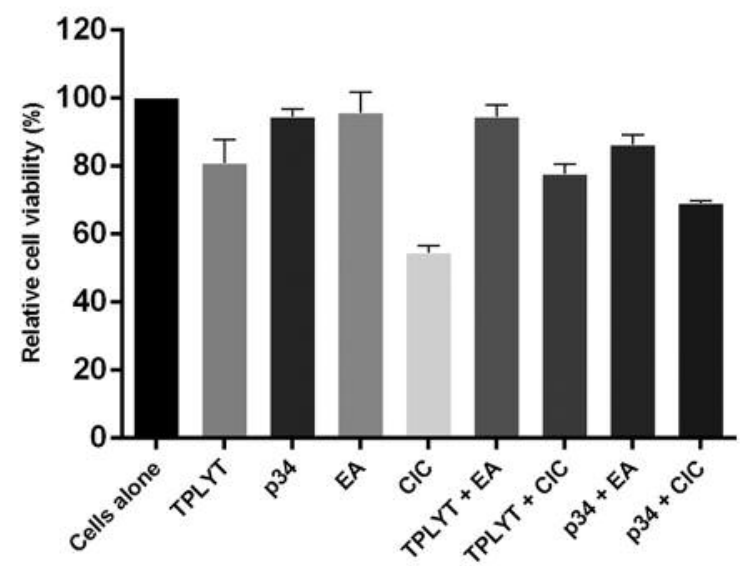

Figure 2. Combination of inhibitors of wingless-related integration site (WNT) and peptides increases cytotoxicity towards prostate cancer cells. Toxicity of the single peptides ( 34 and TP-LYT), single WNT inhibitors [ethacrynic acid (EA) and ciclopiroxolamine (CIC)] and their combinations was evaluated using WST-8 24 h after treatment. Healthy colonic fibroblasts (CCD18co) were used as control. Data shown are the mean \pm SEM of experiments performed in triplicate. A: DU145 cell line, drug concentrations: $160 \mu M$ TP-LYT, $40 \mu M$ p34, $50 \mu M$ EA, $50 \mu M$ CIC. B: BM1604 cell line, drug concentrations: $320 \mu M$ TP-LYT, $160 \mu M$ p34, $50 \mu M$ EA, $50 \mu M$ CIC. C: $22 R v 1$ cell line, drug concentrations: $320 \mu M$ TP-LYT, 160 $\mu M$ p34, $75 \mu M$ EA, $150 \mu M$ CIC. D: LNCaP cell line, concentration of the drugs: $320 \mu M$ TP-LYT, $320 \mu M$ p34, $150 \mu M$ EA, $150 \mu M$ CIC. E: PC3 cell line, drug concentrations: $80 \mu M$ TP-LYT, $80 \mu M$ p34, $75 \mu M$ EA, $75 \mu M$ CIC. F: CCD18co cell line, drug concentrations: $160 \mu M$ TP-LYT, $160 \mu M$ p34, $75 \mu M$ EA, $50 \mu M$ CIC. Significantly different at $* p<0.05, * * p<0.01, * * * p<0.001$ and $* * * * p<0.0001$ compared to the control. 
charged structure. The strong cytotoxicity of p34 was surprising since it was designed to be an inert peptide. It consists of the same lytic domain as TP-LYT, but should exhibit a non-functional target domain. However, in many cases, the toxicity of p34 was higher than that of TP-LYT. This should be studied better in further experiments.

EA and CIC are already used in humans. EA is a diuretic agent and has been shown to induce cell death in different cancer cells $(23,24)$. EA inhibits GST leading to higher oxidized GSH levels in cells, which could be the reason for cell death since oxidative stress is increased. However, (8) studying the mode of action of EA, showed that apoptosis is independent of the GSH level. Another way in which EA might be able to reduce cell viability is through interaction with the lymphoid enhancer-binding factor-1 (LEF1) leading to destabilization of the LEF1- $\beta$-catenin complex (25).

CIC has antifungal effects and has been shown to be cytotoxic towards different cancer cells such as myeloma and lymphoma cells (26- 29). CIC can affect cells in different ways. As mentioned above, it is an iron chelator and can inhibit ribonucleotide reductase, resulting in apoptosis (30). CIC also plays a role in blocking or slowing down the cell cycle because cyclins (A, B1, D1 and E) and cyclin-dependent kinases (CDK2 and CDK4) are downregulated, arresting cancer cells in $\mathrm{G}_{1} / \mathrm{G}_{0}$ phase (31). Furthermore, the same group demonstrated that cell death in cancer cells after treatment with CIC may be due to a decrease of anti-apoptotic proteins (B-cell lymphoma-XL and survivin) and an increased cleavage of B-cell lymphoma 2. Cell viability after treatment with EA or CIC differed in all prostate cancer cell lines, whereas in the control cell line CCD18co, EA did not reduce the number of viable cells, CIC reduced cell viability by $50 \%$. The reason for this could be that the doses used in our experiments may have been too high. Finally, an additive effect of EA and CIC when used in combination with TP-LYT and p34 was demonstrated. This is because the peptides and WNT inhibitors used in this study lead to cell death in different ways. These results could be clinically important because using combinations of targeted peptides and WNT inhibitors may allow the use lower of concentrations of each drug, thereby reducing toxic side-effects. Further studies including in vivo experiments are necessary to determine the actual value of these findings.

\section{References}

1 Ferlay J, Steliarova-Foucher E, Lortet-Tieulent J, Rosso S, Coebergh JW, Comber H, Forman D and Bray F: Cancer incidence and mortality patterns in Europe: Estimates for 40 countries in 2012. Eur J Cancer 49: 1374-1403, 2013.

2 Miller JR, Hocking AM, Brown JD and Moon RT: Mechanism and function of signal transduction by the WNT/ $\beta$-catenin and $\mathrm{WNT} / \mathrm{Ca}^{2+}$ pathways. Oncogene 18: 7860-7872, 1999.
3 You Z, Saims D, Chen S, Zhang Z, Guttridge DC, Guan KL, MacDougald OA, Brown AMC, Evan G, Kitajewski J and Wang CY: WNT signalling promotes oncogenic transformation by inhibiting c-MYC-induced apoptosis. J Cell Biol 157: 429-440, 2002.

4 He X, Semenov M, Tamai K and Zeng X: LDL receptor-related proteins 5 and 6 in $\mathrm{Wnt} / \beta$-catenin signaling: arrows point the way. Development 131(8): 1663-1677, 2004.

5 Moon RT, Kohn AD, De Ferrari GV and Kaykas A: WNT and $\beta$-catenin signalling: diseases and therapies. Nat Rev Genet 5(9): 691-701, 2004.

6 Dihlmann S and von Knebel Doeberitz M: Wnt/ $\beta$-cateninpathway as a molecular target for future anti-cancer therapeutics. Int J Cancer 113: 515-524, 2005.

7 Barker N and Clevers H: Mining the Wnt pathway for cancer therapeutics. Nat Rev Drug Discov 5: 997-1014, 2006.

8 Aizawa S, Ookawa K, Kudo T, Asano J, Hayakari M and Tsuchida S: Characterization of cell death induced by ethacrynic acid in a human colon cancer cell line DLD-1 and suppression by N-acetyl-L-cysteine. Cancer Sci 94: 886-893, 2003.

9 Nagourney RA, Messenger JC, Kern DH and Weisenthal LM: Enhancement of anthracycline and alkylator cytotoxicity by ethacrynic acid in primary cultures of human tissues. Cancer Chem Pharmacol 26: 318-322, 1990.

10 Hoffman BD, Hanauske-Abel HM, Flint A and Lalande M: A new class of reversible cell cycle inhibitors. Cytometry 12: 26-32, 1991.

11 Daum G: Lipids of mitochondria. BBA - Rev Biomembranes 822: 1-42, 1985.

12 Ellerby HM, Arap W, Ellerby LM, Kain R, Andrusiak R, Rio GD, Krajewski S, Lombardo CR, Rao R, Ruoslahti E, Bredesen DE and Pasqualini R: Anti-cancer activity of targeted proapoptotic peptides. Nat Med 5: 1032-1038, 1999.

13 Ellerby HM, Bredesen DE, Fujimura $\mathrm{S}$ and John V: Hunter-Killer Peptide (HKP) for Targeted Therapy. J Med Chem 51: 5887-5892, 2008.

14 Javadpour MM, Juban MM, Lo W-CJ, Bishop SM, Alberty JB, Cowell SM, Becker $\mathrm{CL}$ and McLaughlin ML: De novo antimicrobial peptides with low mammalian cell toxicity. J Med Chem 39: 3107-3113, 1996.

15 Mai JC, Mi Z, Kim S-H, Ng B and Robbins PD: A Proapoptotic Peptide for the Treatment of Solid Tumors. Cancer Res 61: 7709-7712, 2001.

16 Shadidi M and Sioud M: Identification of novel carrier peptides for the specific delivery of therapeutics into cancer cells. FASEB J 17: 256-258, 2002.

17 Shadidi M and Sioud M: Selective targeting of cancer cells using synthetic peptides. Drug Resist Updat 6: 363-371, 2003.

18 Shadidi M and Sioud M: Selection of peptides for specific delivery of oligonucleotides into cancer cells. In: Ribozymes and siRNA Protocols. New Jersey: Humana Press 252: 569-580, 2004.

19 Sioud M: What Are the Key Targeted Delivery Technologies of siRNA Now In RNA Therapeutics. Edited by Sioud M Totowa, NJ: Humana Press 629: 91-105, 2010.

20 Deutscher SL: Phage display in molecular imaging and diagnosis of cancer. Chem Rev 110: 3196-3211, 2010.

21 Meschenmoser K, Kim Y, Franken S, Nowak M, Feldmann G, Bendas G, Wolfgarten M, Messmer D and Schmidt-Wolf IG: Targeting cancer with a bi-functional peptide: in vitro and in vivo results. In Vivo 27(4): 431-442, 2013. 
22 Jäkel CE, Meschenmoser K, Kim Y, Weiher H and Schmidt-Wolf IG: Efficacy of a proapoptotic peptide towards cancer cells. In Vivo 26(3): 419-426, 2012.

23 Schmidt M, Sievers E, Endo T, Lu D, Carson D and SchmidtWolf IG: Targeting Wnt pathway in lymphoma and myeloma cells. Br J Haematol 144(5): 796-798, 2009.

24 Tew KD, Bomber AM and Hoffman SJ: Ethacrynic acid and piriprost as enhancers of cytotoxicity in drug resistant and sensitive cell lines. Cancer Res 48(13): 3622-3625, 1988.

$25 \mathrm{Lu}$ D, Liu JX, Endo T, Zhou H, Yao S, Willert K and SchmidtWolf IGH: Ethacrynic acid exhibits selective toxicity to chronic lymphocytic leukemia cells by inhibition of the $\mathrm{Wnt} / \beta$-catenin Pathway. PLoS ONE 4(12): e8294, 2009.

26 Kim Y, Alpmann P, Blaum-Feder S, Krämer S, Endo T, Lu D, Carson D and Schmidt-Wolf IG: Increased in vivo efficacy of lenalidomide by addition of piroctone olamine. In Vivo 25(1): 99-104, 2011.

27 Kim Y, Alpmann P, Blaum-Feder S, Krämer S, Endo T, Lu D, Carson D and Schmidt-Wolf IG: In vivo efficacy of griseofulvin against multiple myeloma. Leuk Res 35(8): 1070-1073, 2011.

28 Kim Y, Reifenberger G, Lu D, Endo T, Carson DA, Gast SM, Meschenmoser K, Nowak M and Schmidt-Wolf IG: Influencing the wnt signaling pathway in multiple myeloma. Anticancer Res 31: 725-730, 2011.
29 Kim Y, Schmidt M, Endo T, Lu D, Carson D and Schmidt-Wolf IG: Targeting the Wnt/beta-catenin pathway with the antifungal agent ciclopirox olamine in a murine myeloma model. In Vivo 25: 887-893, 2011

30 Eberhard Y, McDermott SP, Wang X, Gronda M, Venugopal A, Wood TE, Hurren R, Datti A, Batey RA, Wrana J, Antholine WE, Dick JE and Schimmer AD: Chelation of intracellular iron with the antifungal agent ciclopirox olamine induces cell death in leukemia and myeloma cells. Blood 114(14): 3064-3073, 2009.

31 Zhou H, Shen T, Luo Y, Liu L, Chen W, Xu B, Han X, Pang J, Rivera CA and Huang S: The antitumor activity of the fungicide ciclopirox. Int J Cancer 127(10): 2467-2477, 2010.

Received November 15, 2016

Revised December 8, 2016

Accepted December 21, 2016 